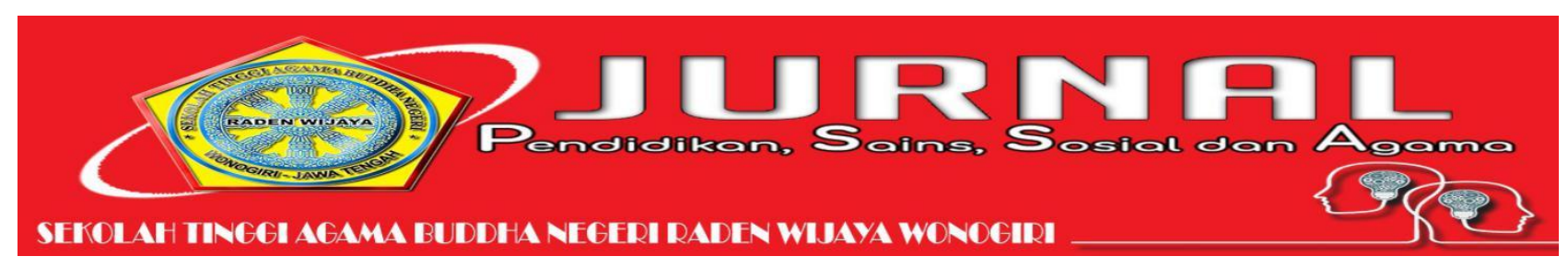

\title{
MAKNA SIMBOLIK RITUAL RUWATAN SATU SURO DI CANDI SIMA
}

\author{
Noviyana Dwi Dayanti \\ STABN Raden Wijaya
}

Email: noviyanadwii@gmail.com

\begin{abstract}
Abstrak
Tujuan penelitian tersebut untuk mengetahui sejarah dan prosesi pelaksanaan ritual ruwatan satu sura di Candi Sima dan makna simbolik ritual ruwatan satu sura di Candi Sima Desa Blingoh Kecamatan Donorojo Kabupaten Jepara. Metode Penelitian yang digunakan dalam penelitian ini adalah metode penelitian deskriptif kualitatif, pengambilan sampel yang di gunakan untuk menjaring sebanyak mungkin informasi dari berbagai macam sumber dengan menggunakan teknik analisis data dalam penelitian ini dimulai dari mengumpulkan, memilah, mengolah dan menganalisis data menggunakan analisis model interaktif. Makna simbolik ritual ruwatan yang ada di Candi Sima adalah untuk menolak bala membersihkan diri dari marabahaya.
\end{abstract}

Kata kunci: Ritual Ruwatan, Candi Sima

\begin{abstract}
The purpose of this study was to see the history and procession of the ritual implementation of the one sura ruwatan ritual at Sima Temple and the symbolic meaning of the ruwatan one sura ritual in Sima Temple, Blingoh Village, Donorojo District, Jepara Regency. The research method used in this research is descriptive qualitative research method, sampling is used to capture as much information as possible from various sources using data analysis techniques in this study starting from collecting, sorting, processing and analyzing data using interactive model analysis. The symbolic meaning of the ruwatan ritual in Sima Temple is to refuse reinforcements to rid themselves of danger.
\end{abstract}

Keywords: Ruwatan Ritual, Sima Temple 


\section{PENDAHULUAN}

Tradisi merupakan warisan masa lalu yang dilestarikan terus hingga sekarang, dapat berupa nilai, norma sosial, pola tingkah laku dan adat kebiasaan lain yang merupakan wujud dari berbagai aspek kehidupan (Imam Banawi, 1993:23-24). Malam satu sura sangat lekat dengan budaya Jawa, tradisi malam satu sura menitik beratkan pada ketrentraman batin dan keselamatan. Karenanya pada malam satu sura biasanya selalu diselingi dengan ritual pembacaan doa, hal ini dilakukan untuk mendapatkan berkah dan menangkal datangnya marabahaya. Tradisi sudah mengakar dimasyarakat salah satunya adalah tradisi ritual ruwatan yang ada di tanah Jawa. Dalam masyarakat Jawa ruwatan adalah salah satu bentuk upacara atau ritual penyucian yang hingga saat ini tetap di lestarikan. Dengan upacara tradisi tersebut diharapkan agar pelaku upacara senantiasa hidup dalam keadaan selamat. Salah satu tradisi yang masih melekat dan sering dilakukan di masyarakat Jawa adalah tradisi ritual ruwatan satu sura yang terdapat di Jawa Tengah khususnya di Candi Sima Desa Blingoh Kecamatan Donorojo Kabupaten Jepara. Pada era modern sekarang banyak umat Buddha yang ingin membangun satu momentum yang sangat sakral di dalam Agama Buddha yaitu dengan membangun sebuah candi yang untuk pertama kalinya di bumi Nusantara dengan berbahan baku batu tanpan semen ataupun besi dan bahan-bahan lainya yang berunsur kimia. Candi tersebut adalah candi yang digunakan untuk melakukan upacara keagamaan baik dari agama Buddha ataupun agama Hindu yang sekarang di kenal dengan Candi Sima. Pada saat menjelang pergantian tahun baru Jawa atau malam satu sura selalu diadakan upacara ritual ruwatan jika dilakukan oleh umat Buddha maka seluruh umat Buddha berkumpul membacakan doa dan melakukan pradaksina kemudian melakukan ritual ruwatan dan ketika dilakukan oleh agama Hindu maka umat Hindu berkumpul dan berdoa sesuai dengan kepercayaan agama Hindu. Ritual ruwatan dianggap dekat dengan hal-hal yang mistis di mana mengingatkan pada kepercayaan animisme yang dianut para nenek moyang terdahulu. Terlihat dari sajian sesajen pada setiap ritual ruwatan digelar, sesajen ini terdiri dari buah-buahan,sayuran, dan bahkan hewan sepeti ayam yang dijadikan sebagai sesajen. Tradisi ruwatan dilakukan dengan serangkaian upacara seperti, doa bersama, sungkeman anak kepada orang tuanya, jemasan (mandi jemas dengan air londho merang). Dalam masyarakat Jawa, ritual ruwat dibedakan menjadi tiga golongan besar yaitu, rituwal ruwat untuk diri sendiri, rituwal ruwat untuk lingkungan dan rituwal ruwat untuk wilayah. Ritual ini dilakukan untuk berdoa agar diberikan keselamatan dan menghilangkan marapetaka dengan menyambut tahun baru penanggalan Jawa identik dengan melakukan ritual ruwatan malam satu sura selalu ada wayang dan ketika ada pertunjukan wayang selalu diberikan sesaji berupa ingkung ayam dengan cara memesan ayam yang sudah selesai masak atau ayam yang sudah matang agar tidak terjadi pelanggaran sila yang pertama (panatipata veramani sikkhapadam samadiyami)) yang berati saya bertekad untuk melatih diri tidak melakukan pembunuhan (Paritta Suci, 2005:26). Buddha telah menjelaskan mengenai upacara yang sukses "brahma". Dalam pelaksanaan upacara tidak ada sapi, kambing, unggas, babi, yang dibunuh atau tidak ada mahluk manapun yang di bunuh (sutta pitaka digha nikaya IV kutadata sutta).

\section{METODE}

Metode Penelitian yang digunakan dalam penelitian ini adalah metode penelitian deskriptif kualitatif. Metode penelitian kualitatif digunakan sebagai prosedur penelitian yang menghasilkan data deskriptif yaitu data yang terkumpul berbentuk kata-kata, gambar dan bukan angka-angka. Dengan demikian, laporan penelitian ini berisi kutipan-kutipan data dalam menyajikan laporan, dimana data tersebut berasal dari hasil wawancara romo pandita ,juru kunci, dan pengurus candi yang ada di Candi Sima Desa Blingoh Kecamnatan Donorojo Kabupaten Jepara, catatan lapangan ( peneliti mendatangi Candi Sima yang akan dilakukan riset) foto (hasil kegiatan penelitian) dan dokumen lainnya (Moleong, 2013:11). Sebelum melakukan wawancara peneliti menentukan subjek penelitian yang akan diteliti oleh peneliti adalah romo 
pandita, juru kunci dan pengurus di Candi Sima untuk mengetahui makna simbolik tradisi ritual ruwatan di Candi Sima Desa Blingoh Kecamatan Donorojo Kabupaten Jepara. Setelah menentukan subjek penelitian maka dilakukan pengambilan sampel, yang di gunakan untuk menjaring sebanyak mungkin informasi dari berbagai macam sumber. Setelah melakukan pengambilan sampel kemudian pengumpulan data, pengumpulan data merupakan langkah yang sangat penting menjadi inti dalam sebuah penelitian langkah yang dilakukan peneliti adalah observasi, menurut pendapat Sugiono (2012: 66) observasi adalah teknik pengumpulan data untuk mengamati perilaku manusia, proses kerja, dan gejala-gejala alam, dan responden.

\section{HASIL}

Kabupaten Jepara adalah salah satu kabupaten di Provinsi Jawa Tengah. Ibu kotanya adalah Jepara. Kabupaten ini berbatasan dengan Laut Jawa di barat dan utara, Kabupaten Pati dan Kabupaten Kudus di timur, serta Kabupaten Demak di selatan. Wilayah Kabupaten Jepara juga meliputi Kepulauan Karimunjawa, yang berada di Laut Jawa. Kabupaten Jepara identik dengan sebutan kota ukir sejak abad ke-19 ukiran Jepara memiliki ciri khas yang menunjukkan bahwa ukiran itu berasal dari Jepara melalui corak dan motifnya. Daerah Jepara telah dikenal luas sebagai daerah yang memproduksi mebel dan ukiran yang terkenal di Indonesia. Jepara juga terkenal dengan destinasi wisatanya dari yang perbukitan hingga pantai dan tempat wisata lainya seperti Pantai Bandengan, Pantai Bondo, Pantai Gua Manik, Benteng Portugis, Pantai Mpu Rancak, Pantai Teluk Awur, Hutan Pinus, Wisata Desa Tempur, Kali Mmbo, Bukit Bejangan, Bukit Distoroto, Pulau Mandalika, Pulau Panjang, Kura-Kura Ocean Park, Musium R,A Kartini, Pulau Karimunjawa dan lain sebagaiya yang sering didatangi oleh wisatawan baik dari dalam negri ataupun dari luar negeri.
Lokasi yang digunakan peneliti untuk meneliti tentang Makna Simbolik Ruwatan Satu Sura di Candi Sima Desa Blingoh Kecamatan Donorojo Kabupaten Jepara berada di Desa Blingoh dukuh Sima RT. 4 Rw.4 Kecamatan Dororojo Kabupaten Jepara Jawa Tengah yaitu bagian Jepara timur. Lokasi Candi Sima cukup strategis karena dekat dengan jalan raya yaitu Jl. Tayu-Jepara, jika dari pasar kelet lurus terus kemudian setelah ada gapura selamat datang Desa Blingoh belok ke kAnan dan kemudian lurus lalu ada plang yang menunjukan arah ke Candi Sima. Jarak dari gapura desa Blingoh ke Candi Sima kira-kira 500 meter. Desa Blingoh masuk Kecamatan Donorojo Jepara, terletak $30 \mathrm{~km}$ di sebelah Utara Kota Jepara. Desa Blingoh terdapat di antara perbatasan Kecamatan Donorojo dengan Kecamatan Keling. Di sebelah utara berbatasan langsung dengan Desa Jugo, Desa Tulakan, Desa Ujungwatu, Desa Banyumanis, dan Desa Clering. Sebelah selatan Berbatasan dengan Desa Kelet dan Desa Mojo Kecamatan Cluwak Kabupaten Pati. Sedangkan sebelah timur berbatasan dengan Desa Jugo dan Desa Ujungwatu. Sedangkan di sebelah barat berbatasan dengan Desa Kelet Dan Desa Mojo Keamatan Cluwak Kabupaten Pati.

Secara Administrasi Desa Blingoh terdiri dari Lima perdukuhan besar dan 7 RW yaitu Dukuh Krajan (RW.01 berjumlah 10 RT), Dukuh Cangaan (RW.02 berjumlah 7 RT, RW.03 berjumlah 7 RT) Dukuh Simo(RW.04 berjumlah 6 RT,Senggrong RW.05 berjumlah 4 RT), Dukuh Lembah (RW.06 berjumlah 10 RT),Dukuh Guwo(RW.07 berjumlah 8 RT). Di Desa Blingoh terdapat juga beberapa tempat wisata yang menarik dan presentatif. Diantaranya, Danau Blingoh di Dukuh Lembah, Air Terjun Undak Manuk, dan Air Terjun Manten (Air Terjun Lanang Wedok) di Dukuh Senggrong.

Warga Desa Blingoh mayoritas beragama Islam, Buddha dan Kristen. Penduduk Desa 
Blingoh $90 \%$ berasal dari Suku Jawa, dan $10 \%$ keturunan Portugis. bahasa keseharian masayarakat Desa Blingoh adalah Bahasa Jawa, meskipun Bahasa Indonesia adalah bahasa resmi, umumnya sebagian besar masyarakat menggunakan Bahasa Jawa sebagai bahasa sehari-hari atau biasa dikenal dengan istilah Bahasa Jawa Dialek Jeporonan. Pendidikan masyarakat Desa Blingoh ratarata lulusan SMP sederajat. Pekerjaan masayarat Desa Blingoh yaitu, petani, buruh, pegawai, wirausaha dan wiraswasta.

Candi Sima dibangun pada awal tahun 2012 dan sampai sekarang masih dalam proses pembangunan. Candi Sima berada di bawah naungan Yayansan Eka Sagara Dharma. Di Candi Sima sering dilakukan ritual ruwatan pada malam satu sura. Selain digunakan sebagai tempat ritual ruwatan satu sura di Candi Sima juga di gunakan sebagai tempat untuk melakukan puja keagamaan Agama Hindu. Ruwatan adalah suatu adat Jawa untuk membersihkan diri, yang bertujuan untuk menolak bala jauh dari mara bahaya. Ruwatan juga bisa untuk pembersihan alam semsesta supaya damai, sejahtera jauh dari bencana. Sejarah ruwatan di Candi Sima adalah implementasi dari ajaran Agama dan adat budaya bisa berjalan bersama karena agama tidak lepas dari tradisi dan dimana manuia tinggal disitu menyatu dengan dengan tradisi adat dan budaya yang ada. Karena hidup di daerah Jawa maka terbiasa dan menyatu dengan tradisi Jawa. Sejarah ruwatan di Candi Sima adalah implementasi dari ajaran Agama dan adat budaya bisa berjalan bersama karena agama tidak lepas dari tradisi dan dimana manusia disitulah manusia akan menyatu dengan tradisi adat dan budaya yang ada. Menurut Jacobus Ranjabar (2006: 1) dalam Ida Fitria (2018: 31) dalam kehidupan manusia, agama dan budaya tidak dapat berdiri sendiri, keduanya memiliki hubungan yang sangat erat dan tidak dapat dipisahkan, agama sebagai pedoman dalam hidupa manusia dalam menjalani kehidupannya sedangkan budaya adalah suatu kebiasaan tata cara hidup manusia yang diciptakan oleh menusia sendiri dari hasil daya cipta, rasa dan karsanya yang diberikan oleh Tuhan. Karena hidup di daerah Jawa maka menyatu dengan tradisi Jawa.

Sejarah ruwatan dalam agama Buddha sendiri berasal dari kisah Tantra yang membentuk ajaran Buddha di Jawa yang sesuai dengan kondisi wilayah yang ada dikerajaan wilayah pada masa itu dan di bangunlah Borobudur yang digunakan sebagai sesi untuk ruwatan, yang di Borobudur sendiri mempunyai 4 sisi penjuru. Pada jaman dahulu mulai dari Rangkai Pikatan itulah agama Hindu dan Buddha berdampingan maka disebutlah Hindu buddha disitulah ritual ruwatan diakui bersama. Berkelanjutan dibangunlan Borobudur pada masa Wangsa Syailendra dan Sanjaya, oleh karena itu Bodobudur di bangun dengan mandala segi empat (empat penjuru alam) untuk sesi ruwatan. Pada jaman dahulu ruwatan dilakukan pada hari raya Magha Pujja. Sesi ruwatan itu sendiri mengambarkan pembersihan diri manusia dan dibuatlah sebuah ritual ruwatan sebagai tolak bala memohon perlindungan dan pembersihan diri. Dalam agama Buddha ruwatan bisa degan membacakan doa bersama, meditasi bersama. Jaman sebelum Majapahitpun sudah ada ruwatan dan kemudian dilanjutkan oleh kerajaan Majapahit. Pada masa itu pada jaman keemasan Sri Maharaja Rangkai Watukura Dyahbahlitung Darmodaya Mahasambu adalah raja kerajaan Medang pada tahun 899911 disitulah Dharma berkembang sangat baik sesi-sesi ruwatan sprituwal keagamaan berkembang sangat baik, namun pada masa itu masih menggunakan Bahasa Jawa kuno.

Tokoh pembawa ritual ruwatan di Candi Sima adalah Resi Vajra Dawara Eko Karyono dan pertama kali ritual ruwatan di Candi Sima 
pada Tahun 2012. Hal yang mendasari ritual ruwatan bisa menjadi suatu acara atau kegiatan yang rutin dilakukan setiap tahunya di Candi Sima supaya adat bisa berjalan terus dan tetap lestari maka harus dilakukan dan dijalankan terus supaya tidak hilang dengan berjalanya waktu sehingga nanti akan menjadi adat dan budaya. Ritual ruwatan dilakukan dan bertujuan untuk menolak bala atau mala petaka. Tidak ada syarat apapun jika ingin mengikuti ritual ruwatan satu sura di Candi Sima, hal yang terpenting adalah niat karena tanpa ada niat tidak akan bisa tergerak untuk melakukan suatu hal. Prosesi ritual satu sura di Candi Sima dilakukan dengan membacakan doa-doa dari Paritta Suci mapun mantra, dan biasanya dilakukan terpisah kebaktian dilakukan trantrayana terlebih dahulu menggunakan mantra dan secara umum nenggunakan Paritta Suci. Busana atau pakain yang digunakan dalam ruwatan satu sura di Candi Sima biasanya memakai baju putih agar lebih sakral dan berseragam. Ketika akan melakukan ritual ruwatan biasanya pada waktu satu sura dan dilakukan pada pukul 12 malam karena bersifat sakral yang biasanya dilakukan di area Candi dengan membacakan doa bersama dilanjutkan dengan prosesi pradaksina mengkelilingi Candi Sima. Bahasa yang digunakan dalam ritual ruwatan di Candi Sima menggunakan Bahasa Nasional dan Bahasa Jawa. Yang terlibat dalam prosesi rituwal ruwatan dari anggota Sanggha, umat Buddha, para pengurus Candi Sima, umat non-Buddhis pun diperbolehakan untuk mengikuti ritual ruwatan yang ada di Candi Sima. Tidak hanya dari sekitar Candi Sima saja yang mengikuti ritual ruwatan tetapi hampir dari seluruh Indonesia bahkan dari luar Negeripun ada. Pada saat prosesi ritual ruwatan saru sura di Candi Sima umat yang mengikuti di siram air kembang dan pemotongan rambut sedikit, seperti ucapara ruwatan pada umunya dan kemudian potongan dari rambut tersebut dilarungkan ke laut dan saat pelarungan tersebut juga ada ritualnya tersendiri. Makna simbolis berasal dari bahasa yunani yaitu "syimbolos" yang berati tanda atau ciri yang memberitahukan hal kepada seseorang (menurut Herusatoto, 1991:10). Makna simbolik ritual ruwatan yang ada di Candi Sima adalah untuk menolak bala membersihkan diri dari marabahaya. Dalam agama Buddha mengenal dengan pembersihan diri, pembersihan diri berarti membersihkan pikiran karena pikiran adalah pelopor dari segala perbuatan. Melalui pikiran seseorang akan berucap dan bertindak, melalui pikiran juga seseorang akan mempertmibangkan apa yang akan di ucapkan dan dilakukan. Pikiran yang bersih mendorong seseorang untuk melakan hal yang positif begitupun sebaliknya. Dalam Dhammapada, syair 1-20 Yamaka Vagga (syair berpasangan), Buddha mengatakan bahwa pikiran adalah pelopor dari segala sesuatu. Buddha menyadari pentingnya kerja pikiran. Dari ketiga jenis perbuatan, ucapan, perbuatan dan jasmani. Buddha mengakui perbuatan melalui pikiran adalah yang terkuat. Dengan adanya ritual ruwatan saru sura tersebut dengan melakukan pembersihan diri maka sama halnya dengan melakukan pembersihan pikiran agar pikiran bersih jika pikiran bersih maka akan ada hal-hal positif yang muncul yang dan tidak akan ada membahayakan diri manusia. Karena pada dasarnya mara bahaya yang datang pada diri seseorang muncul karena pikiran, ucapan dan perbuatan seseorang itu sendiri. Dalam rituwal ruwatan satu sura yang ada di Candi Sima terdapat beberapa komponen-komponen seperti berikut:

1. Dupa; dupa tiga batang, karena ini mewakili Pikiran, Ucapan dan Perbuatan. Jadi ketika seorang umat Buddha memasang dupa tiga, itu artinya mampu mengendalikan pikiran, ucapan dan perbuatan. Di arahkan untuk mewangikan 
sekeliling seseorang, mewangikan lingkungan, jadi kepada orang tua selalu mewangikan dengan pikiran yang baik, ucapan yang baik dan perbuatan yang baik, kepada teman juga demikian, bahkan kepada musuh sekalipun.

2. Lilin; lilin adalah cahaya atau penerangan batin yang akan melenyapkan kegelapan batin dan mengusir ketidaktahuan (avijja). Bunga; bunga menggambarkan ketidakkekalan (anicca).

3. Bunga segar yang diletakkan di altar setelah berganti waktu dan hari akan menjadi layu. Begitu pula dengan badan jasmani seseorang, suatu waktu kelak pasti akan menjadi tua, sakit, lapuk akhirnya meninggal.

4. Air; menggambarkan kerendahan hati. Dikatakan demikian karena air selalu mencari tempat yang lebih rendah dimanapun mengalir. Air memiliki juga memiliki sifat, yaitu dapat membersihkan noda, menjadi sumber kehidupan makhluk, dapat menyesuaikan diri dengan semua keadaan, selalu mencari tempat yang lebih rendah, meskipun kelihatannya lemah, tetapi dalam keadaan tertentu dapat bangkit menjadi tempat yang dahsyat (misal banjir, tsunami, dan lain sebagainya).

5. Buah; buah-buahan melambangkan buah dari pencapaian spiritual yang membawa seseorang menuju buah akhir, yaitu penerangan sempurna, yang merupakan tujuan akhir semua umat Buddha. Ini mendorong kita untuk berusaha mencapai Penerangan Sempurna bagi kebahagiaan semua makhluk.

6. Bubur panca warna; bubur pancawarna terdiri dari lima warna dari bendera Buddhis yaitu warna biru (Nila) dari warna rambut Sang Buddha melambangkan bakti atau pengabdian, kuning emas (Pita) dari warna kulit Sang Buddha melambangkan kebijaksanaan, $m$ erah tua (Lohita) dari warna darah Sang Buddha melambang cinta kasih, putih (Odata) dari warna tulang dan gigi Sang Buddha melambang kesucian, jingga (Manjesta) dari warna telapak tangan, kaki dan bibir Sang Buddha yang melambangkan semangat.

7. Sesaji; sesaji disini digunakan untuk wayang, sesaji untuk wayang berupa ingkung ayam dan tumpeng. Tumpeng atau gunungan jika orang jawa menyebutknya dengan nasi buceng yang isinya berupa sayuran "kulup" yang menggambarkan kebesaran alam bahwa alam disekitar bisa memberikan apa yang manusia butuhkan untuk keberlangsungan hidup dan ingkung yang digunakan tidak hasil dari membunuh melainkan ayam yang sudah matang yang telah dipesan melalui catering. Karena dalam agama Buddha diajarkan cinta kasih dan belas kasih tanpa melukai ataupun membunuh mahkluk hidup yang terdapat pada Pancasilla Buddhis Sila pertama yang berbunyi "Pānātipātā veramaṇi sikkhāpadai் samādiyāmi” yang berartikan "Aku bertekad akan melatih diri menghindari pembunuhan makhluk hidup". Terdapat pada (Sutta Majimma Nikaya: Jivaka Majima)

8. Kembang setaman: yang terdiri dari bunga gading, kenanga, melati, kamboja, kantil, soka dan mawar. Yang menggambarkan para kaula muda yang sedang berkembang. Dari beragam bunga tersebut juga terdapat bunga yang mewakili.

\section{KESIMPULAN}

1. Sejarah ruwatan di Candi Sima adalah implementasi dari ajaran Agama dan adat budaya bisa berjalan bersama karena agama tidak lepas dari tradisi dan dimana kita tinggal itu menyatu dengan dengan 
tradisi adat dan budaya. Prosesi ritual satu sura di Candi Sima dilakukan dengan membacakan doa-doa dari Paritta Suci mapun mantra, dan biasanya dilakukan terpisah kebaktian dilakukan trantrayana terlebih dahulu menggunakan mantra dan secara umum nenggunakan Paritta Suci kemudian melakukan pradaksina mengkelilingi Candi Sima kemudian melakukan siraman air kembang setaman dan pemotongan rambut dari para peserta yang mengikuti ritual ruwatan tersebut. Potongan rambut tersebut akan dilarungkan ke laut yang akan ada ritualnya tersendiri. Busana atau pakain yang digunakan dalam ruwatan satu sura di Candi Sima biasanya memakai baju putih agar lebih sakral dan berseragam. Ketika akan melakukan ritual ruwatan biasanya pada waktu satu sura dan dilakukan pada pukul 12 malam karena bersifat sakral yang biasanya dilakukan di area Candi. Bahasa yang digunakan dalam rituwal ruwatan di Candi Sima menggunakan Bahasa Nasional dan Bahasa Jawa. Yang terlibat dalam prosesi rituwal ruwatan dari anggota Sanggha, umat Buddha para pengurus Candi Sima, umat non-Buddhis pun diperbolehakan untuk mengikuti ritual ruwatan yang ada di Candi Sima.

2. Makna simbolik ritual ruwatan yang ada di Candi Sima adalah untuk menolak bala membersihkan diri dari marabahaya. Dalam agama Buddha mengenal dengan pembersihan diri, pembersihan diri berarti membersihkan pikiran karena pikiran adalah pelopor dari segala perbuatan. Melalui pikiran seseorang akan berucap dan bertindak, melalui pikiran juga seseorang akan mempertmibangkan apa yang akan di ucapkan dan dilakukan. Pikiran yang bersih mendorong seseorang untuk melakan hal yang positif begitupun sebaliknya. Dalam ritual ruwatan satu sura banyak komponen-komponen yang digunakan dan memiliki makna-makna tersendiri seperti dupa, bunga, buah, air, lilin, dan bubur lima panca warna yang ada di altar. Kemudian kembang setaman untuk melakukan prosesi siraman dan sesaji yang digunakan untuk wayang yang isinya berupa sayuran "kulup" dan ingkung ayam, namun ingkung yang digunakan tidak hasil dari membunuh melainkan ayam yang sudah matang yang telah dipesan melalui catering. Karena dalam agama Buddha diajarkan cinta kasih dan belas kasih tanpa melukai ataupun membunuh mahkluk hidup yang terdapat pada Pancasilla Buddhis Sila pertama yang berbunyi "Pānātipātā veramaṇī sikkhāpadai் samādiyāmi” yang berartikan "Aku bertekad akan melatih diri menghindari pembunuhan makhluk hidup". Terdapat pada (Sutta Majimma Nikaya: Jivaka Majima)

\section{Daftar Pustaka}

1. Burgin, M. Burhan. 2008. Penelitian Kualitatif. Jakarta : Kencana Pradana Media.

2. Fitria, Ida. 2018. Agama dan Budaya Studi Tentang Tradisi Ruwatan Masal di Kelurahan Kadipaten Kabupaten Bojonegoro. Fakultas Ushuluddin dan Filsafat. Universitas Islam Negeri Ampel Surabaya.

Moleong, Lexy. 2013. Metodologi Penelitian Kualitatif. Bandung: PT. Remaja Rosdakarya.

3. Sugiono. 2008. Metode Penelitian Kuantitatif Kualitatif dan $R \& D$. Bandung: ALFABETA.

4. Sugiono. 2012. Memahami Penelitian Kalitatif. Bandung: ALFABETA.

5. Sugiono. 2013. Memahami Penelitian Kaulitatif. Bandung: Alfabeta. 
Jurnal Pendidikan, Sains Sosial dan Agama Volume 7 Nomor 2

6. Yayasan Sangha Theravada Indonesia.

2005. Paritta Succi. Jakarta Utara:

Yayasan Sangha Yheravada Indonesia. 